International Journal of Oceans and Oceanography

ISSN 0973-2667 Volume 14, Number 1 (2020), pp. 101-108

(C) Research India Publications

https://dx.doi.org/10.37622/IJOO/14.1.2020.101-108

\title{
Design of a Rectangular Microstrip Patch Antenna with Edge Feeding Technique for Marine Applications
}

\author{
${ }^{1}$ Dr.V.Nandalal, ${ }^{2}$ Mr.N.Sathishkumar, ${ }^{3}$ Dr.T.Manikandan, \\ ${ }^{4}$ Mr. V. AnandKumar ${ }^{5}$ Ms.G.Indhumathi \\ ${ }^{1,5}$ Department of ECE, Sri Krishna College of Engineering and Technology, \\ Coimbatore. \\ ${ }^{2}$ Department of ECE, KPR Institute of Engineering and Technology, Coimbatore. \\ ${ }^{3}$ Department of ECE,Rajalakshmi college of Engineering ,Chennai. \\ ${ }^{4}$ Department of ECE,Sri Eshwar college of Engineering ,Coimbatore.
}

\begin{abstract}
This proposed method serves purpose of designing a rectangular patch antenna of Micro-strip with $5.2 \mathrm{GHZ}$ as frequency of resonance for marine applications. Design is performed in ANSYS High Frequency Structure Simulator (HFSS). Patch antenna of rectangular is created with FR4epoxy substrate. Reflection coefficient for this design is obtained in $5.2 \mathrm{GHz}$ frequency range. The excitation given to this patch antenna is Edge Feed with a fixed length and width. The performance parameters such as S-parameter, Gain, VSWR, directivity of the antenna is obtained and analyzed for the marine applications.
\end{abstract}

Keywords: ANSYS HFSS, Edge Feed, FR4 epoxy, S-parameter, Gain, Directivity, VSWR.

\section{INTRODUCTION}

Antennas are unit key parts of any wireless communication system. They have the characteristics of converting any type of signal into waves that can be transmitter wirelessly for longer distance. The signal that is transmitted is received by a receiving antenna. The data or the information is transmitted as electromagnetic waves. The receiver antenna has a property of reciprocal process which converts this 
electromagnetic waves into a signal or voltage that is given as input to the other end of a system under communication. The main function of antenna is radiation characteristics. Transmission line defines this. Transmission line which conducts current with uniform velocity, and a straight line with infinite extent does not radiate power.

Antenna of Micro-strip patch is the foremost type of printed antenna. It has a major role in wireless communication systems. Fabrication can be easily done using micro strip antenna. Ground plane, substrate an radiating patch are there in a structure of this antenna. Patch dimensions defines radiating feature of antenna. Length and width parameters are used for representing patch. Material used to make substrate is FR4 epoxy.These materials are durable for a long range of frequency. The frequency ranges used to excite and analyze antenna is $5.2 \mathrm{GHz}$.

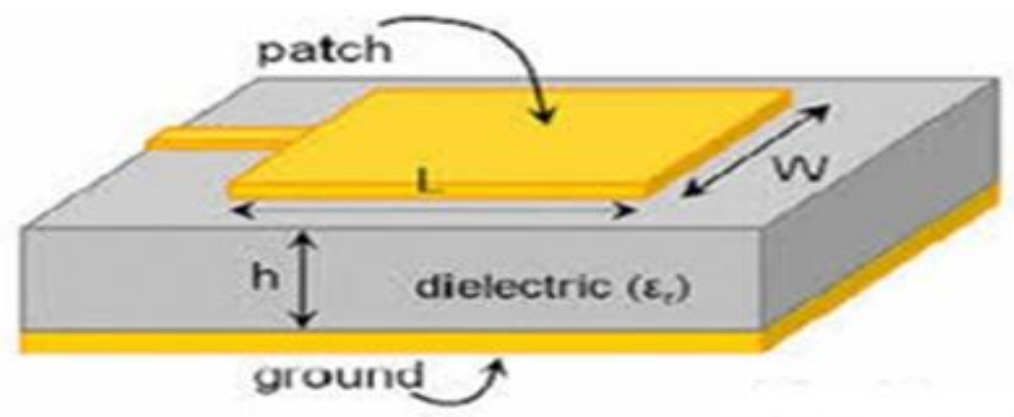

Figure 1.1 Microstrip patch antenna

Antenna design is done in ANSYS High Frequency Structure Simulator (HFSS) tool. It is a 3D simulation tool applicable for high frequency electronic elements as antenna and antenna arrays. This software tool has worldwide application that can be used in wireless communication, radar applications, satellite communication, Internet of things products. It solves the problems in 3D EM design. Complete analysis and provides guaranteed accuracy as result. The parameters necessary to analyse the antenna can be viewed in 2D and 3D model for accurate analysis.

\section{BLOCK DIAGRAM}

The designed antenna can be used to transmit the information from signal processing unit to satellite. The properties of Ocean in underwater are dissolved gases, Salinity, temperature, desnsity, colour can be studied using this microstrip patch antenna at 5.2 Ghz frequency.

Dissolved gases: In seawater, Carbon dioxide, argon,oxygen and nitrogen are the major dissolved gases. In ocean, dissolved gases distribution is controlled by following general factors. A) salinity and temperature, B) biological activity, C) currents and mixing process. At surface, water concentration and with atmosphere in equilibrium, is computed by salinity and temperature. Carbon dioxide and oxygen 
concentration is affected by biological activity. Through eddy diffusion and mass movement, biological activity effect is modified by the process of mixing and current.

Colour: Pure water is impeccably clear, yet in the event that there is a ton of water, and the water is profound so that there are no reflections off the ocean bottom, the water shows up as a dim naval force blue. The explanation the sea is blue is because of the assimilation and dissipating of light. The blue wavelengths of light are dissipated, like the dispersing of blue light in the sky yet ingestion is an a lot bigger factor than dispersing for the reasonable sea water. In water, assimilation is solid in the red and powerless in the blue, subsequently red light is retained rapidly in the sea leaving blue.

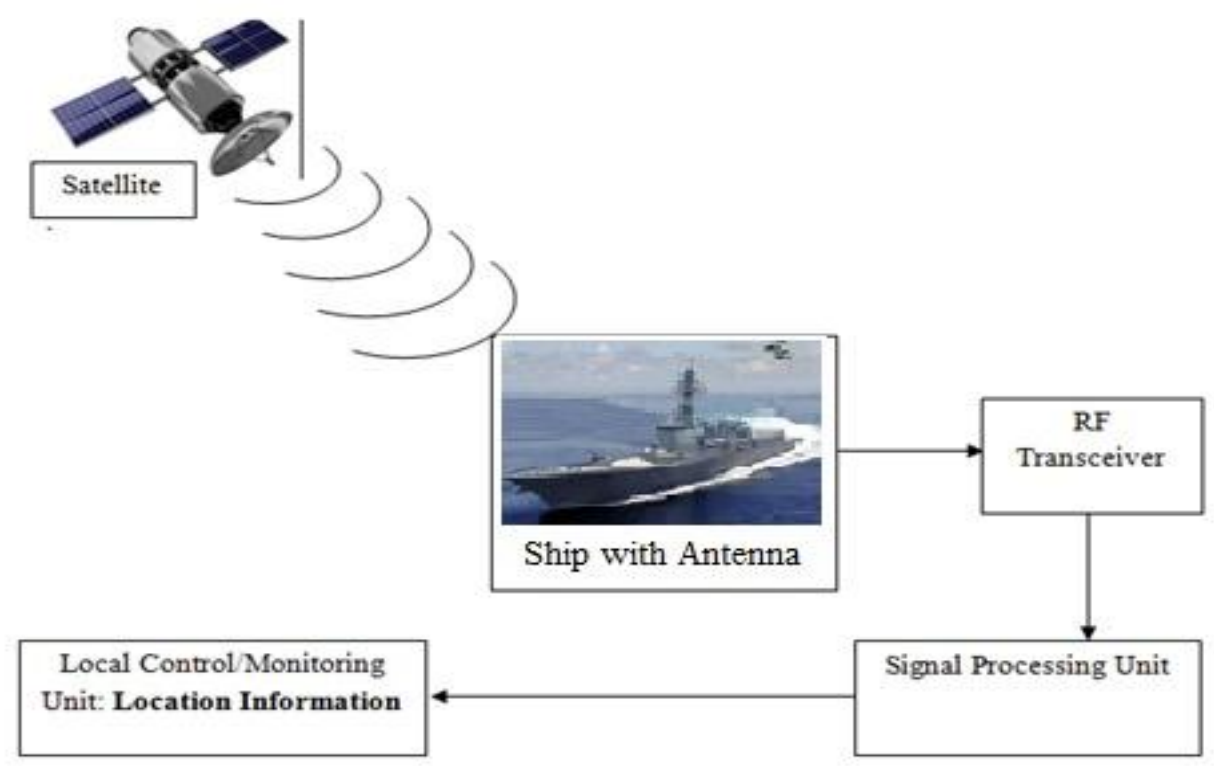

Figure 1.2 Block Diagram

\section{FEEDING TECHNIQUES}

Feeding is the basic process for establishing connection between transmitter and receiver antenna and make them connected for transfer of information. As the antenna operates in radio frequency the feeding is created in same range. The communication between the antenna happens through radio frequency signal.

\subsection{Edge Feed Technique:}

This feeding is provided through a feedline that connects the external edge feed on the substrate with the radiating patch. The design is made such a way that width of feed element is less than radiating patch. 


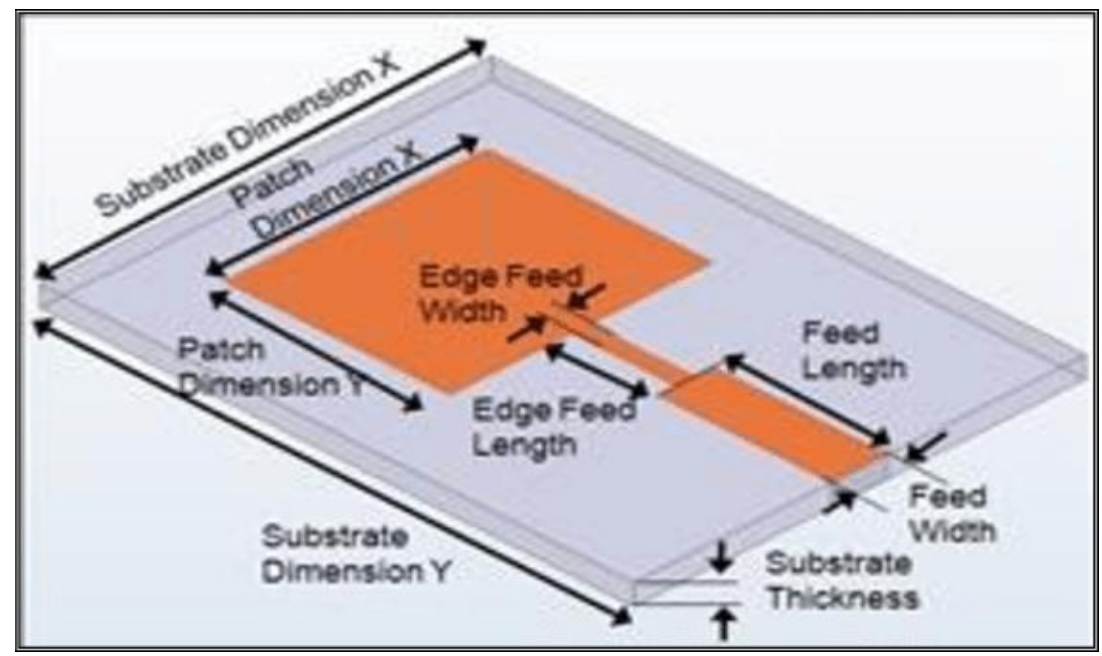

Figure 1.3: edge feed

\section{MICROSTRIP PATCH ANTENNA OF RECTANGULAR DESIGN}

A Rectangular Microstrip Patch Antenna is designed to operate at $5.2 \mathrm{GHz}$ frequency with edge feeding technique. The proposed design is created with the substrate with FR4 epoxy under dielectric constant $\varepsilon_{r}=4.4$. The length of radiating patch is 12.56 $\mathrm{mm}$ and width is $17.56 \mathrm{~mm}$ for edge feed.

The dimensions for designing antenna is calculated as below

For calculating width of the patch ,the following equation is used,

$$
W=\frac{1}{2 f_{r} \sqrt{\mu_{0} \varepsilon_{0}}} \times \sqrt{\frac{2}{\varepsilon_{r}+1}}
$$

The length can be evaluated as,

$$
L=\frac{1}{2 f_{r} \sqrt{\varepsilon_{e f f}} \sqrt{\mu_{0} \varepsilon_{0}}}-2 \Delta L
$$

Where,

$$
\begin{gathered}
\varepsilon_{e f f}=\frac{\varepsilon_{r}+1}{2}+\frac{\varepsilon_{r}-1}{2 \sqrt{1+12 \frac{\mathrm{h}}{w}}} \\
\Delta L=\frac{\left(\varepsilon r_{e f f}+0.3\right)\left(\frac{w}{\mathrm{~h}}+0.264\right)}{\left(\varepsilon r_{e f f}-0.258\right)\left(\frac{w}{\mathrm{~h}}+0.8\right)} * 0.412 \mathrm{~h}
\end{gathered}
$$




\section{DIMENSIONS OF PROPOSED DESIGN}

Table 1.1: Edge feed technique

\begin{tabular}{|l|c|}
\hline PARAMETERS & EDGE FEED \\
\hline Resonant Frequency(fr) & $5.2 \mathrm{GHz}$ \\
\hline Substrate & FR4 epoxy \\
\hline Dielectric constant & 4.4 \\
\hline HeightofSubstrate & $1.6 \mathrm{~mm}$ \\
\hline Width of Patch & $17.56 \mathrm{~mm}$ \\
\hline LengthofPatch & $12.56 \mathrm{~mm}$ \\
\hline Substrate Length & $58.94 \mathrm{~mm}$ \\
\hline Substrate Width & $35.9 \mathrm{~mm}$ \\
\hline Ground Plane Length & $58.94 \mathrm{~mm}$ \\
\hline Ground Plane Width & $35.9 \mathrm{~mm}$ \\
\hline
\end{tabular}

\section{SIMULATION OUTCOMES}

\subsection{EDGE FEED:}

a) Return Loss:

Power loss is represented by return loss. It is caused because of channel or transmission line discontinuities. Signals are returned due to this in transmission process.

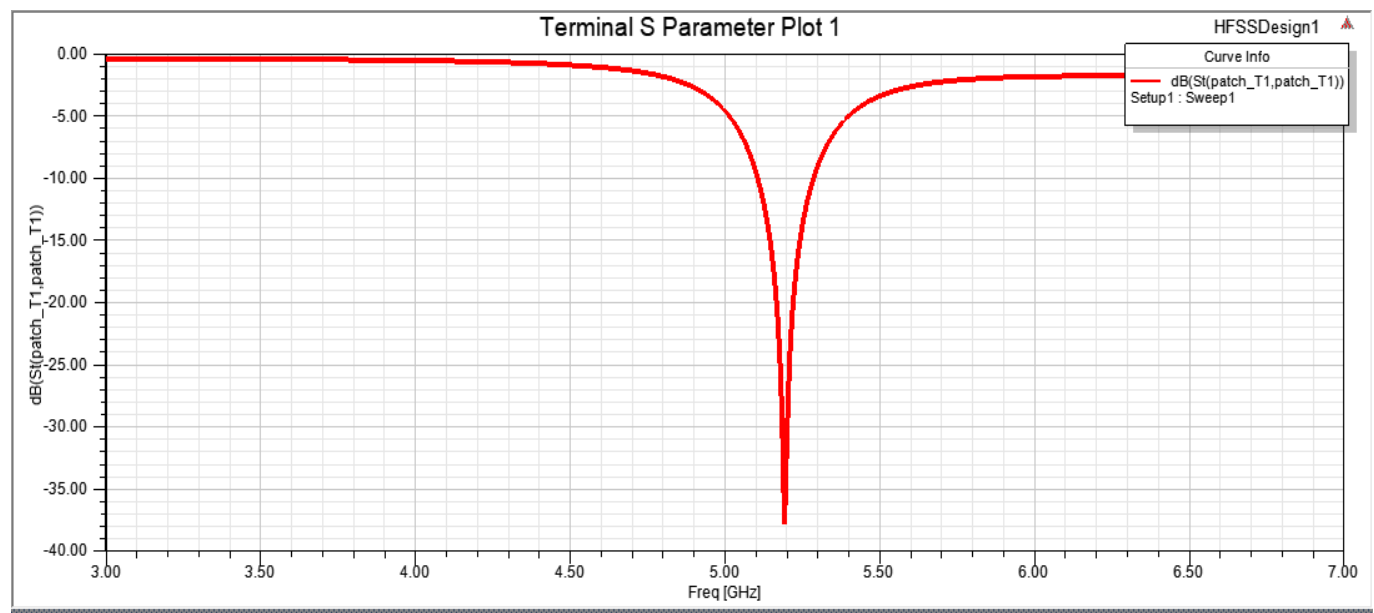

Figure 1.4 Return loss for edge feed

From the above result, it is shows return loss is very narrow at the radiated $5.2 \mathrm{Ghz}$ frequency. This indicates that the antenna exhibits perfect radiation. 
b)VSWR:

VSWR is known as Voltage Standing Wave Ratio .This is analyzed to know about the impedance matching of antenna.

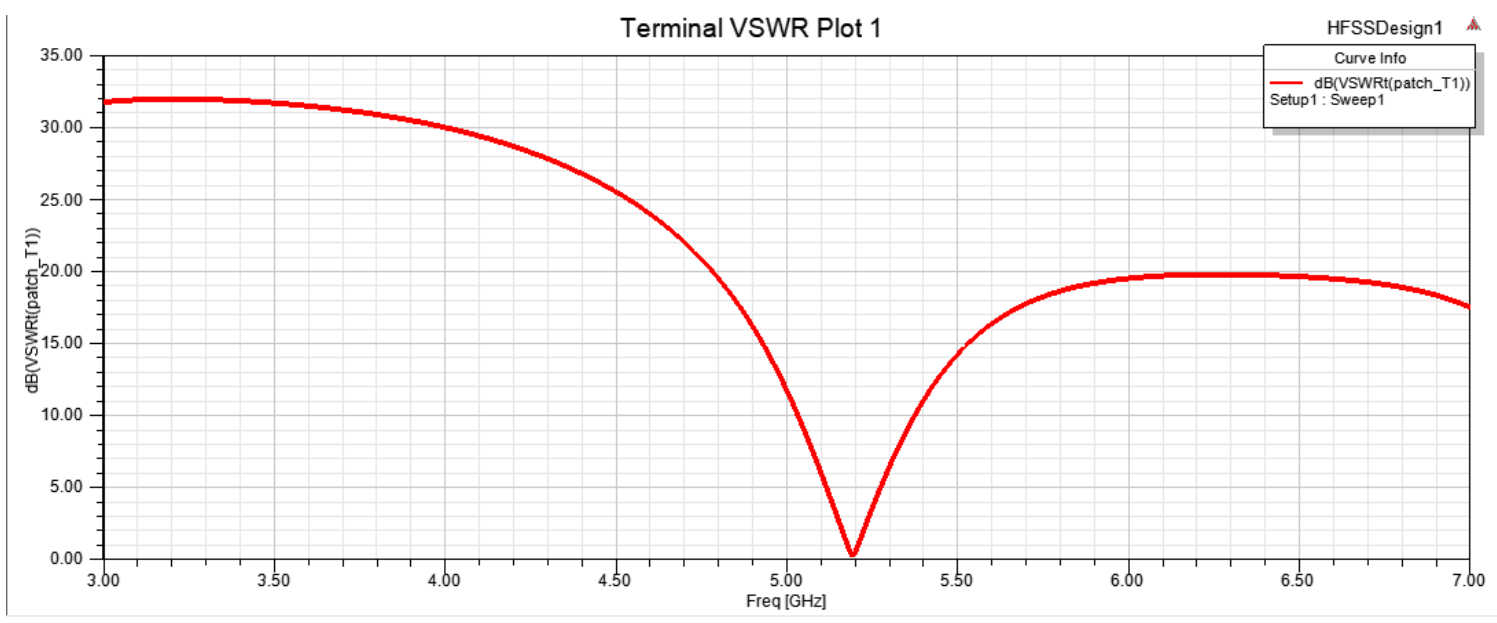

Figure 1.5 VSWR

From the above result it is analyze that in $5 \mathrm{GHz}-5.5 \mathrm{GHz}$ range of frequency, there will be a constant value of VSWR.

c) GAIN:

This describes how much amount of power is radiated from the antenna. The maximum radiation is obtained based in the frequency applied. If the value obtained is not optimized then the performance of antenna is low.
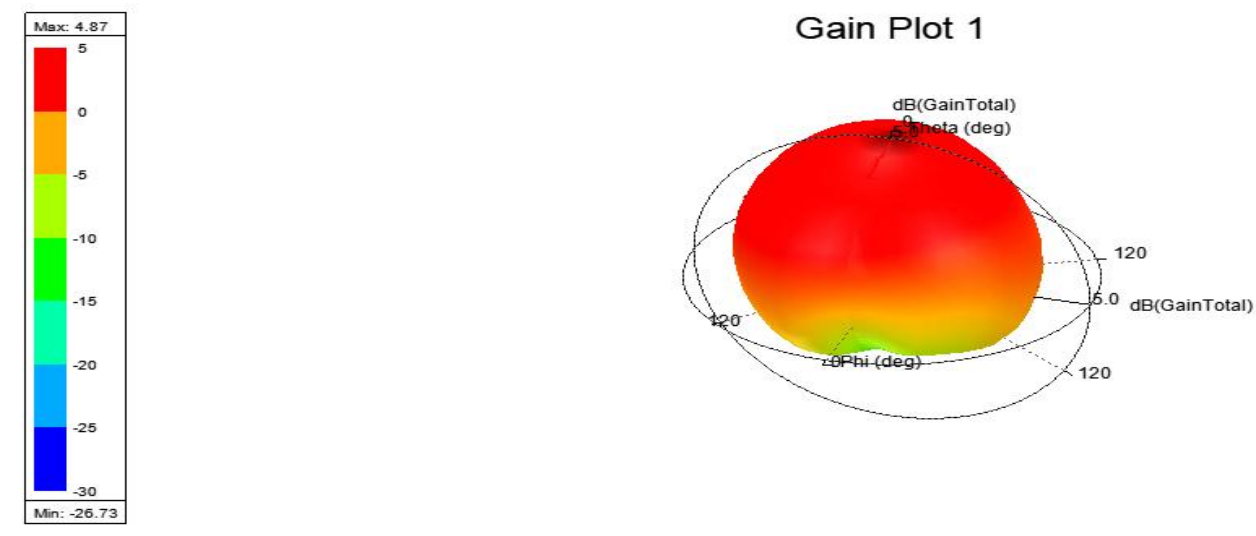

Figure 1.6 Gain 


\section{CONCLUSION}

ANSYS HFSS (High Frequency Structure Simulator) is used for designing patch antenna of micro-strip. Concept can also be developed using that. The edge feeding technique is applied to the antenna that is designed. From the calculated results it is clear that the antenna works accordingly for the marine environment applications.

As the outlook work can be extended to convert the designed antenna into reconfigurable antenna and analyze the performance.

\section{REFERENCES}

[1] P-Y. Qin, Y. J. Guo, and C. H. Liang, "Effect of antenna polarization diversity on MIMO system capacity," IEEE Antennas wireless propag. Lett., vol. 9, pp. 1092-1095, 2010.

[2] R. K. Saini, and S. Dwari, "CPW-fed broadband circularly polarized rectangular slot antenna with L-shaped feed line and parasitic elements", Microw. Opt. Technol. Lett., vol. 57, no. 8, pp. 1788-1794, Aug. 2015.

[3] Yong-XinGuo; Kah- Wee Khoo; Ling Chuen Ong "Wide bandCircularly Polarized Patch Antenna Using Broadband Baluns"Antennas and Propagation, IEEE Transactions on Volume 56, Issue2, Feb. 2008.

[4] A.H.M. ZahirulAlam, Md. Rafiqul Islam and Sheroz Khan "Design and Analysis of UWB Rectangular Patch Antenna ", Pacificconference on applied electromagnetiggs proceedings, December 4-6, 2007, Malaysia.

[5] J-H. Lu, and S-F. Wang "Planar broadband circularly polarized antenna with square slot for UHF RFID reader," IEEE Trans. Antennas Propag, vol. 61, no. 1, pp. 45-53, Jan. 2013.

[6] M. Matin, B. Sharif and C. Tsimenidis, "Probe-fed stacked patch antenna for wideband applications," IEEE Transactions on Antennas and Propagation, vol. 55, no. 8, pp. 2385- 2388, Aug. 2007.

[7] B. Ooi, S. Qin and M. Leong, "Novel design of broad-band stacked patchantenna," IEEE Transactions on Antennas and Propagation, vol. 50, no.10, pp. 1391-1395, Oct. 2002.

[8] Z. Liu, P. Kooi and L. Li, "A method for designing broad-band microstripantennas in multilayered planar structures," IEEE Transactions on Antennas and Propagation, vol. 47, no. 9, pp. 1416-1420, 1999.

[9] F. Croq and A. Papiernik, "Stacked slot-coupled printed antenna," IEEEMicrowave and Guided Wave Letters, vol. 1, no. 10, pp. 288-290, Oct.1991.

[10] K. Ding, C. Gao, B. Zhang, Y. Wu and D. Qu, "A compact printed unidirectional broadband antenna with parasitic patch," IEEE Antennasand Wireless Propagation Letters, vol. 16, pp. 2341-2344, 2017. 
[11] Y. Sung, "Bandwidth enhancement of a microstrip line-fed printedwide-slot antenna with a parasitic center patch," IEEE Transactions on Antennas and Propagation, vol. 60, no. 4, pp. 1712-1716, April 2012.

[12] S. Wi, Y. Lee and J. Yook, "Wideband microstrip patch antenna withu-shaped parasitic elements," IEEE Transactions on Antennas and Propagation, vol. 55, no. 4, pp. 1196-1199, April 2007.

[13] K. Lee, K. Luk, K. Tong, S. Shum, T. Huynh and R. Lee, "Experimentaland simulation studies of the coaxially fed u-slot rectangular patchantenna," IEE Proceedings - Microwaves, Antennas and Propagation, vol.144, no. 5, pp. 354358, Oct. 1997. 